\title{
El problema del acceso a los fondos documentales de las cooperativas eléctricas
}

\author{
The problem of access to the documentary of the electric \\ cooperatives
}

Beatriz R. Solveira*

\begin{abstract}
RESUMO
El reciente descubrimiento del cooperativismo eléctrico como objeto de estudio por la historiografía argentina no ha dado como resultado demasiadas investigaciones que arrojen luz acerca de un fenómeno que comienza a producirse en el país a partir de la segunda mitad de la década de 1920. Probablemente la cuestión no haya interesado aún a muchos colegas, probablemente también tal interés exista pero se vea limitado por las dificultades para acceder a las fuentes propias de las cooperativas y al desconocimiento de otras fuentes que, si bien no pueden suplirlas totalmente, sin embargo, son complementarias de aquéllas y en algunos casos pueden llegar a suplirlas parcialmente. El objetivo de este trabajo es precisamente reflexionar acerca de esta cuestión, analizándola tanto desde el punto de vista de los cambios teóricos que se han producido en las últimas décadas en el estudio de los hechos económicos como desde la importancia de los fondos documentales de las cooperativas, con el fin de descubrir algunas posibles vías que conduzcan a una más amplia y efectiva utilización de los archivos de las cooperativas. Pero este breve artículo no es solamente una reflexión que quiero compartir con los colegas, sino que además pretende ser una invitación a las autoridades de las cooperativas eléctricas a abrir sus archivos al trabajo de los historiadores.
\end{abstract}

PALAVRAS-CHAVE: Argentina, fondos documentales, cooperativas eléctricas.

\section{ABSTRACT}

The recent discovery of the electric cooperative as a subject for study in historiography Argentina has not resulted in many investigations that shed light on a phenomenon that begins to occur in this country since the second half of the 1920s. Probably no issue has concerned many colleagues still likely that interest also exists but is limited by the difficulties of access to sources of cooperatives own and ignorance of other sources, although they can not replace entirely, however, they are complementary and in some cases can be partially filled. The aim of this paper is to reflect on this issue, analyzed from the viewpoint of the theoretical changes that have occurred in recent years in the study of economic events or on the importance of the documentary of cooperatives in order to discover possible pathways that lead to a wider and effective use of the archives of cooperatives. But this brief article is not just a reflection that I want to share with colleagues, but also intended as an invitation to the authorities of the electric cooperatives to open their files to the work of historians.

KEYWORDS: Argentina, documentary, electric cooperatives.

Doutora em História. Professora da Universidad Nacional de Córdoba (UNC) e da Universidad Católica de Córdoba (UCC). Pesquisadora do Consejo Nacional de Investigaciones Científicas y Técnicas (CONICET) e do Centro de Estudios Históricos "Prof. Carlos S. A. Segreti” / Argentina. 
Si bien el fenómeno cooperativista es uno de los nuevos campos en el que los historiadores argentinos han comenzado a incursionar desde hace algún tiempo, entre las distintas experiencias de ese movimiento, la relacionada con el sector eléctrico muestra aún una notable escasez de trabajos, pese al singular desarrollo alcanzado por el cooperativismo eléctrico y a que su surgimiento estuvo íntimamente ligado a la preocupación por la situación de la industria eléctrica argentina, que en su momento caló hondo entre los socialistas y entre los miembros del Museo Social Argentino, cuyo accionar a favor del movimiento cooperativista se inicia ya a fines de la segunda década del siglo XX y que desde los albores de la década de 1930 promovió con gran fuerza la formación de cooperativas eléctricas. Por cierto que esa promoción dio lugar, desde entonces y hasta nuestros días, a la publicación de numerosos y reveladores trabajos libros y artículos- escritos por cooperativistas, ${ }^{1}$ por intelectuales interesados en la defensa de los consumidores de electricidad ${ }^{2}$ y por estudiosos provenientes de otras disciplinas sociales que han estudiado la cuestión desde muy distintas ópticas. 3

Desde una perspectiva estrictamente histórica, en cambio, es recién en los últimos años que comienza a observarse un cierto interés sobre el tema a través de estudios encaminados a analizar las etapas de desarrollo de las cooperativas, de su gestión empresaria y de las principales variables de su evolución económica, e integrando en sus análisis múltiples factores -no solamente económicos sino también políticos, sociales y personales- que intervinieron en los procesos locales, y aportando desde una mirada micro nuevos elementos para la comprensión del movimiento cooperativo eléctrico argentino. Esos estudios -centrados en la trayectoria de una cooperativa en particular- se diferencian de los hasta ahora producidos tanto por especialistas en otras

1 De este tipo de obras se pueden citar las publicaciones de la Asociación de Productores y Distribuidores de Electricidad y de la Editorial Intercoop, y los estudios de Alfredo Victorino. Callejo (1986 y 1999), Enrique Corona Martínez, Raúl Isidoro D’Atri y Diego Andrés López.

2 A fines de la década de 1930, Baltasar V. Jaramillo y Jorge del Río dieron cuenta, desde una mirada general, del creciente desarrollo alcanzado por las cooperativas eléctricas, constituyendo sus estudios una fuente de obligada consulta para los investigadores actuales. En la misma línea, pero más cercanos en el tiempo, se encuentran también los artículos de Guillermo Benjamín Zubiaur y de José Mario Cremaschi.

3 Tal es el caso del aporte hecho por los economistas Ramón Frediani, Luis Branca, Domingo Sesín y Eduardo Ingaramo, quienes en 1986 publicaron los resultados de una investigación sobre transferencia de servicios públicos a empresas cooperativas en la provincia de Córdoba, en el que junto a las cooperativas eléctricas estudian también las que brindan otros servicios públicos urbanos. 
disciplinas como por algunos historiadores que abordaron y abordan el cooperativismo eléctrico de manera general y, además, han sido generados desde la perspectiva de la historia de empresas, que es una línea de investigación que en realidad tiene una larga tradición en la historiografía argentina, pero que a partir de la década de 1980, como consecuencia de la crisis de los modelos macro sociales que planteó a los historiadores nuevas preguntas y también la necesidad de buscar nuevos soportes conceptuales para su trabajo empírico, se ha visto renovada por la incorporación de enfoques teóricos que han contribuido a enriquecerla y que han servido para despertar ese nuevo interés por el estudio de las cooperativas como un tipo especial de empresa.

Dentro del modesto florecimiento de los estudios que han encarado la historia del cooperativismo eléctrico desde esta nueva perspectiva, destaca obviamente el trabajo pionero de Andrea Lluch y Laura Sánchez sobre el origen y desarrollo de la Cooperativa Popular de Electricidad de Santa Rosa (La Pampa) entre 1925 y 1950, pero a él se suman otros posteriores, como los de Gustavo Chalier y Luciano Izarra (sobre la Cooperativa de Punta Alta), de Luis Rodrigo La Scaleia (sobre la Cooperativa de Las Flores), de Dedier Norberto Marquiegui y María Teresa Tartaglia (sobre la Cooperativa de Luján) y de María Elena Rodríguez (sobre la Cooperativa de Río Tercero).

De todos modos, salta a la vista la escasez de trabajos sobre esta temática y cabe preguntarse cuál es la razón que inhibe, o por lo menos limita, su estudio. Una posible respuesta a ese interrogante es que este vacío en la historiografía argentina es consecuencia tanto de intereses -por ejemplo, una mayor atracción por otro tipo de temáticas-, como de inconvenientes operativos que debe enfrentar el historiador. Me refiero a los problemas relacionados con las fuentes inadecuadas y/o inexistentes y con las dificultades para su consulta, que frenan la posibilidad de reconstruir la historia de las cooperativas con toda la riqueza y seriedad del trabajo científico y que ameritan una serena reflexión que desde las dificultades avance hacia las necesarias soluciones.

El objetivo de este trabajo es precisamente reflexionar sobre la segunda de esas posibles respuestas, analizándola tanto desde el punto de vista de los cambios teóricos que se han producido en las últimas décadas en el estudio de las cuestiones económicas como desde la importancia de los fondos 
documentales de las cooperativas, con el fin de descubrir algunas posibles vías que conduzcan a una más amplia y efectiva utilización de los archivos de las cooperativas. Pero este breve artículo no es solamente una reflexión que quiero compartir con los colegas, sino que también pretende ser una invitación a las autoridades de las cooperativas eléctricas a abrir sus archivos al trabajo de los historiadores.

Del mismo modo que los individuos, las organizaciones generan documentos que constituyen la memoria, el conocimiento -"un conocimiento inmediato de lo que se planea, de lo que se hace, de lo que se acaba de hacer y de lo que se hizo"- porque, a diferencia de los individuos, las organizaciones necesitan documentar minuciosa y exhaustivamente todos sus actos "para alimentarse de información estable y constatable de las cuentas, de los resultados, de los clientes, del personal, del entorno [...] y el conjunto organizado de ese conocimiento que abarca desde ahora hacia atrás, es el archivo". (CRUZ MUNDET, 2005)

La necesidad de que los archivos de empresa salieran del olvido fue descubierta hace ya bastante tiempo en los países donde la historia empresarial se convirtió tempranamente en una preocupación de los historiadores y en los que por tanto esa línea de investigación tiene una más larga trayectoria. Más recientemente, mientras esa experiencia se trasladaba a otros países, aparecieron además nuevas perspectivas de análisis relacionadas con la investigación económica y el interés por esos archivos cobró nueva fuerza, al calor de la búsqueda de un espectro cada vez más amplio de fuentes que permitieran encarar en profundidad el estudio de la historia individual y sectorial de las empresas. Obviamente, ese interés de los investigadores por las fuentes empresariales dio lugar al surgimiento de una mayor preocupación por el rescate y conservación de los archivos empresariales y por el descubrimiento de la riqueza informativa que ellos contienen. En América Latina una prueba de ese interés es el volumen que hace pocos años una revista mexicana dedicó a las fuentes empresariales. 4

Desde luego que la renovación sufrida por la tradicional historia de

4 América Latina en la historia económica. Boletín de fuentes, Instituto de Investigaciones Dr. José María Luis mora, Número 15, enero-junio 2001. 
empresas ha contribuido a reafirmar la utilidad y la importancia de los fondos documentales de las empresas para el conocimiento del pasado tecnológico e industrial de las comunidades donde ellas han actuado, pues ha puesto en evidencia que esos archivos, en su origen privados, con el tiempo adquieren un valor tal para esas comunidades que los convierte en un bien propio y por lo tanto pierden "la imagen de lugar secreto y cerrado, que es un mero testigo del pasado, sin ningún valor en el presente”. (GONZÁLEZ PEDRAZA, 2006) A su vez, bajada al mundo de las cooperativas, esta comprobación asume una importancia mayor no siempre tenida en cuenta y esa importancia deriva de las características propias de la cooperativa en la que por lo general participan, sea en forma directa, sea indirecta, todos los miembros de su comunidad. Es decir, la cooperativa es una entidad que está totalmente comprometida y en permanente contacto con ellos, cumpliendo una función que no es solamente económica sino también social y cultural y por lo tanto el conocimiento de su pasado enriquece el acervo cultural del medio en el que se desenvuelve su actividad.

En lo que se refiere a la preocupación por la conservación y difusión de los archivos de empresa, que tiene larga data tanto en los Estados Unidos como en la Europa occidental y que fue el fruto de la iniciativa emprendida por agentes privados, en unos casos procedentes de las propias firmas y en otros de las instituciones vinculadas a ellas o cercanas a los propios investigadores económicos, sabemos que no es una experiencia que se haya dado del mismo modo en el ámbito latinoamericano y tampoco en la Argentina, donde esos fondos -cuando existen- no son los mejor conservados y donde ese descuido alcanza también a la conservación y ordenamiento de los fondos documentales públicos, en los que tampoco es fácil ubicar y consultar esos materiales. La experiencia española es, en cambio, bien distinta. En efecto, tradicionalmente en España no sólo hubo una mayor preocupación por la conservación y ordenamiento de los archivos públicos sino que, cuando hace unas tres décadas irrumpe allí el interés por la historia empresarial, los españoles apostaron en forma decidida por dar a conocer la importancia y el estado de unos fondos documentales hasta entonces prácticamente desconocidos.

A este respecto, la Argentina ofrece un escenario que se acerca a la experiencia latinoamericana más que a la española y que en el caso específico 
del cooperativismo eléctrico indica, inexorablemente, que estamos frente a un largo camino que hay que comenzar a transitar. Además, aquí la utilidad de los archivos de ese tipo de cooperativas es por ahora conocida sólo por los historiadores, especialmente aquéllos que han pretendido incursionar en la historia del movimiento cooperativo eléctrico, pero no por los poderes públicos y menos aún por quienes conducen a esas cooperativas. Los consejos de administración y mucho más los asociados de estas entidades desconocen el valor de la misión de todo archivo que es recoger, organizar y custodiar el patrimonio documental conservado a través del tiempo y en consecuencia tampoco saben, pero es imprescindible hacerles saber, que el estudio sobre sus fondos documentales puede ofrecerles una panorámica de la trayectoria de la cooperativa, que además de realidades económica y humana, es un sujeto geográfico, un escenario que se desarrolla en el tiempo, pero también en el espacio, implicando en su evolución a todo su entorno porque lo transforma mediante la actividad que realiza (suministro de energía eléctrica) o la creación de infraestructuras (usinas y canalizaciones de transporte y distribución de energía).

No obstante, es justo señalar que sí se observa un cuidadoso respeto de las disposiciones legales relacionadas con la conservación de la documentación de toda sociedad comercial. En la República Argentina la primera ley que rigió el accionar de las cooperativas fue la Ley Nacional de Cooperativas $\mathrm{N}^{0} 11.388$, que se sancionó en diciembre de 1926; esta ley fue el punto de partida y gran inspiradora de las leyes de cooperativas de algunos países latinoamericanos y sus principios fundamentales fueron luego mantenidos y ampliados por la nueva Ley de Cooperativas $\mathrm{N}^{\circ} 20.337$, sancionada y promulgada el 2 de mayo de 1973. Ahora bien, aunque ésta es mucho más completa, tanto una como otra ley impusieron a las cooperativas la obligación de organizar un sistema de contabilidad acorde con su respectiva actividad y de aplicar, subsidiariamente, las prescripciones del Código de Comercio sobre sociedades anónimas, en cuanto no fuesen contrarias. En consecuencia, las cooperativas quedaron obligadas a llevar los libros diario, inventario y balance exigidos por el art. 44 de ese código, a los que el art. 38 de la ley 20.337 agregó el registro de asociados y los libros de actas de asambleas, de actas de reuniones del consejo de administración y de informes de auditoría. En cuanto a la conservación de esos 
libros de comercio rige también lo dispuesto por aquel código, que en su art. 67 establece la obligación de conservar toda esa documentación durante 10 años.

Desde la perspectiva de la historia de empresas, la información esencial para el estudio de las cooperativas eléctricas proviene, sin ninguna duda, de las fuentes de la propia cooperativa; sin embargo, los consejos de administración de esas sociedades manifiestan una gran reticencia a poner esos fondos al alcance de los investigadores, como todos los que incursionamos en la historia del cooperativismo eléctrico hemos podido comprobar con harta frecuencia. Es verdad que por desgracia, en muchos casos, esa información no está disponible porque no ha sido debidamente conservada por las sociedades o porque éstas ya no se encuentran en funcionamiento y se desconoce el paradero de sus archivos, 5 pero, por lo general, el motivo de aquella limitación obedece fundamentalmente a un excesivo celo por parte de los integrantes de los consejos, quienes invariablemente desconfían de cualquier extraño que intente consultar los papeles societarios, aunque también a cuestiones operativas, entre las que destacan la desorganización de sus archivos y la falta de personal y espacio adecuado para atender a los investigadores. Como consecuencia de ello, los historiadores, cuando más, podemos consultar las actas de esos consejos, que son material inédito, y los informes y memorias anuales, que en no pocos casos están publicados. El resto de la documentación, toda ella inédita y mucho más desagregada, que conforma lo que podemos calificar propiamente como archivo de empresa, permanece por tanto fuera del alcance de la mirada del historiador, aunque su curiosidad científica puede ser satisfecha en parte por la información complementaria que proporciona la actuación de la administración pública -en primer lugar la municipal, pero también la provincial y, en menor grado, la nacional-, en la que es posible ubicar registros de la actividad societaria y que todos sabemos se guardan en archivos públicos. ${ }^{6}$

\footnotetext{
5 En el caso del movimiento cooperativo eléctrico argentino es frecuente encontrarnos con entidades que ya no están en actividad, lo que constituye por cierto una dificultad adicional para el investigador, porque en este caso sus archivos han desaparecido. Al respecto es conveniente recordar que los fondos documentales de las empresas pueden ser abiertos o cerrados. Son abiertos aquéllos que pertenecen a sociedades aún activas, en las que los documentos siguen creándose día a día y sólo con el paso del tiempo adquieren el carácter de históricos. Son archivos cerrados los que han sido generados por organizaciones que ya no están en actividad.

$6 \mathrm{Al}$ estudiar el frustrado proyecto de creación de la Sociedad Cooperativa de Electricidad de Córdoba, en la década de 1930, pude comprobar que cuando no es posible consultar los papeles de una cooperativa, por la razón que sea -que en este caso es porque desapareció hace mucho
} 
En general es bastante raro que los poderes públicos impongan a las empresas la obligación de conservar los documentos por un plazo de tiempo más largo de aquel que es considerado necesario para su propio funcionamiento, y menos aún la obligación de dar a la publicidad sus archivos, especialmente para la investigación histórica. Por lo tanto esto depende exclusivamente de la empresa y de su necesidad de continuidad histórica como también de su deseo de mantener su propia imagen ante el público, y en el caso de las cooperativas ante sus socios. Pero, aunque las empresas estén obligadas por la ley a conservar pocos documentos, existen aspectos de su actividad cotidiana que deben ser documentados -a saber: los contratos comerciales, las escrituras de propiedad, de compra-venta, los expedientes del personal, etc.con un fin probatorio indispensable para la empresa, la que a través de ellos puede hacer valer sus derechos y justificar sus actos. Pero además de esa función probatoria, los documentos de empresa tienen también una doble función informativa: es memoria interna de la empresa y, a la vez, fuente de información externa, y ambas funciones son útiles al historiador.

Sin embargo, tenemos la impresión de que los archivos de las cooperativas parecen esconderse del historiador, haciendo que los resultados de sus investigaciones sea una historia por demás incompleta, sobre todo cuando resulta a todas luces evidente que no se puede hacer la historia de una cooperativa sin tener acceso a sus papeles, aún cuando se cuente con otro tipo de documentación -cualquiera ella sea- ya que la misma bien poco nos dirá acerca de (la cooperativa) tal entidad mientras que sus papeles, en cambio, nos dirán casi todo. Al mismo tiempo, también observamos que lamentablemente los fondos documentales de las cooperativas eléctricas son un conjunto de documentos desorganizados que sólo podrán ser debidamente útiles a los investigadores en la medida en que los consejos de administración decidan difundir el patrimonio documental de su institución, sacándolo del olvido, organizándolo y elaborando las guías que son tan útiles. Por eso es tan necesario como urgente encarar de una vez la cuestión y buscar de alguna manera que esa situación se revierta, convenciendo a los dirigentes y asociados de las cooperativas que los archivos son útiles tanto para nuestras investigaciones

tiempo y no se sabe el destino habido con sus archivos-, existe no obstante la posibilidad de encontrar en los archivos oficiales algunos datos que arrojan alguna luz sobre su historia. 
como para mejorar la gestión empresarial.

Según ya se dijo, el desinterés de las cooperativas por sus fondos documentales, que representan la memoria de su transcurrir por la actividad económica a la que se dedican, es al menos en el caso de las eléctricas un verdadero problema para la labor histórica. Por eso la necesidad de hacerles ver a sus consejos de administración que pertenecer a la cooperativa significa conocer sus finalidades, los objetivos que persigue, conocer su historia, su prestigio, su misión y que esos documentos son el testimonio de la memoria colectiva y un elemento de identidad único de la cooperativa y que mucho les ayudaría en su actividad presente el disponer de un archivo organizado y que su difusión redundaría también en beneficio de la comunidad en la que desenvuelve esa actividad. Un buen archivo es el puente entre el pasado y el presente y significa seguridad para los documentos y la información, tan importantes durante como después de su utilidad inmediata. Claro está que muy "difícilmente se pueda constatar la utilidad de algo inexistente [...] o de algo que no está disponible o cuya existencia se ignora cuando puede ser útil para la entidad", (CRUZ MONDET, 2005) o cuando el archivo ocupa una posición muy marginal en la organización porque a él va a parar lo que ya no sirve y ha perdido su valor de uso corriente, convirtiéndose en un simple depósito donde se conserva aquello que no ha sido destruido. (SCORTEGAGNA, 1992) En este caso, es obvio que si el archivo carece de interés para la empresa, la que tampoco lo ve como un objeto de interés para terceros -la administración pública o los investigadores-, poco hará para facilitar su proyección fuera de ella y sobre todo que se plantee "para qué dedicar recursos para una función que no es estrictamente necesaria a sus propias finalidades, sino que sirve a la de otros”, (CRUZ MONDET, 2005) aunque en algún caso recurra a él con fines conmemorativos y haga posible trabajos inscriptos en la más tradicional historia empresarial.

En tren de argumentar a favor del cambio, es necesario destacar que la historia es la transmisión selectiva de ese patrimonio que es el archivo,7 el que

7 Con "transmisión selectiva" se alude a la imposibilidad de describir una totalidad y a que, en consecuencia, toda descripción se hace de ese modo. En este sentido ya Marc Bloch advirtió que el "auténtico problema de acción" de todo historiador es, "frente a la inmensa y confusa realidad", señalar "el punto particular de aplicación de sus útiles" (BLOCH, 1982: 22) porque, como luego afirmara Paul Veyne, "es imposible narrar la totalidad del devenir y hay que elegir" (VEYNE, 1984: 36). Por lo tanto, al elegir el itinerario que va a seguir para describir el campo de 
nos acerca a los orígenes, propósitos, identidad, tradición y cultura de la cooperativa en el tiempo, y que es asimismo una herramienta de diagnóstico y de análisis retrospectivo, pues el conocimiento del pasado de la cooperativa es un medio de evaluación y de planificación, que puede ayudar a corregir los errores y las imprevisiones al momento de tomar decisiones. Por otra parte, como "el presente es un momento en la trayectoria del pasado al futuro", el reconstruir su historia puede constituir una manera de pensar en la cooperativa y de comprender por qué "el presente es el que es y como puede ser para hacer posible el futuro". (SMITH Y STEADMAN, 1981: 165) Si ello se comprendiera, en vez de bloquear el acceso a la investigación de su pasado, las cooperativas mostrarían una mejor predisposición para facilitar la consulta de sus archivos y permitir que los investigadores accedan a ellos, con autorización previa, sin que esto altere sus derechos sobre la documentación, pero haciendo posible la recuperación de ese patrimonio que devuelve la memoria de sus realizaciones técnicas y humanas, a la par que permite comprender la esencia de la cooperativa desde sus orígenes.

Pero, claro está, es a nosotros los historiadores a quienes nos corresponde la ardua tarea de adoctrinamiento en la que debemos explicar y proclamar qué son y para qué sirven los archivos de las cooperativas a fin de lograr un cambio en la actitud de (los cooperativistas) sus miembros. Es decir, a los historiadores se nos impone la tarea de hacerles ver que "historia e interés empresarial se dan la mano" (CRUZ MONDET, 2005) y que la historia de la cooperativa tiene un valor que va más allá de la celebración de un aniversario, por muy emotivo que sea, y que es útil para el aprendizaje y la mejora de su gestión. Así como asegurarles que, en contrapartida, los investigadores que pretendan hacer uso de sus fondos documentales han de asumir el compromiso de "no atacar ni herir la honorabilidad de las personas físicas o jurídicas cuyos datos puedan recogerse en los documentos que consulten y a ceñir su consulta únicamente para fines de estudio e investigación”. (GONZÁLEZ PEDRAZA, 2006) En lo que resta de esta reflexión se intentará aportar otros argumentos que puedan apoyar la tarea que nos aguarda, comenzando primero por un breve inventario de los contenidos de esos fondos y aludiendo luego al compromiso de interdisciplinariedad que

acontecimientos que estudia, el historiador efectúa siempre una selección de la información que le brinda un archivo. 
supone la historia de empresa.

Obviamente, el fondo documental de una cooperativa contiene un repertorio muy rico en información si bien con frecuencia incompleto, sea por los expurgos realizados a lo largo del tiempo, sea por las pérdidas motivadas por otras muy diversas razones. Además, casi siempre se presenta muy desagregado y difícil de trabajar. Es más, la experiencia nos dice que en lo que se refiere a los repertorios documentales de las cooperativas eléctricas hay que tener siempre presente que son muy pocas, o casi ninguna, las sociedades que conservan prácticamente intacta la documentación generada por su historia y que el problema mayor que el investigador enfrenta, en el inusual caso de que se le permita trabajar con tales materiales, es que el archivo o fondo documental de la cooperativa, que seguramente no ha sido catalogado por ningún archivero profesional, posee una lógica interna que él deberá descubrir sin mayores demoras si quiere que su trabajo avance a buen ritmo.

Entre las fuentes que forman parte del fondo documental de una cooperativa encontramos, como en cualquier otro tipo de empresa, las actas de asambleas -ordinarias y extraordinarias-y las actas de las reuniones de los consejos de administración, las que si bien suelen ofrecer datos -por lo general cualitativos y muy raramente cuantitativos- de relevancia sobre la cooperativa, no tienen la riqueza informativa de los informes o memorias anuales, que son uno de los documentos que la ley requiere que se elaboren anualmente para que el consejo de administración rinda cuenta por escrito de la marcha de la cooperativa frente a los asociados y a los fiscalizadores durante el período comprendido por el ejercicio cooperativo, incluyendo en la misma perspectivas futuras. Las memorias son, entonces, un instrumento de comunicación entre el órgano de administración y la masa de cooperativistas, que cumple una función complementaria de las actas de reuniones de los consejos de administración en tanto dan a conocer la marcha económica de la cooperativa, las diferentes estrategias empresariales y las más imaginativas soluciones a problemas específicos propuestas por los consejeros y, por lo tanto, en ellas es posible descubrir las grandes líneas de su política; es decir, "leyendo una memoria se advertirá una política u otra aplicada a la institución por su administración”. (JUNYENT VÉLEZ Y BERTOSSI, 1987: 102) 
Además, esas memorias constituyen al mismo tiempo el elemento que proporciona el hilo conductor que permite interpretar adecuadamente las cifras referidas, por ejemplo, a activos, producción, facturación, empleo, beneficios, que se vuelcan en los registros contables, pues en ellas aparecen las cuentas anuales -esto es, las grandes cifras de la sociedad en el periodo- las que con frecuencia son acompañadas con cuadros en los que se las compara con los resultados de años anteriores y que dan cuenta del estado de las instalaciones, del movimiento contable y de los resultados de la producción y venta de energía; estas últimas cuentas son útiles para comprender más ampliamente la política energética de la cooperativa. Esto es, en general, lo que se espera encontrar en las memorias de cualquier tipo de empresa o cooperativa, pero veamos concretamente qué es lo que sucede con las memorias de las dos cooperativas cuyas memorias hemos tenido oportunidad de consultar.

En las memorias de las cooperativas de Río Tercero y de Córdoba, sus consejos de administración dan cuenta de la labor realizada, informando sobre suscripción de acciones, registro de nuevos socios, aumento del capital social y de consumidores, rescate de acciones, intereses accionarios, retornos, seguros contratados, donaciones recibidas, derechos y gastos de aduana, cuestiones relacionadas con la prestación del servicio eléctrico (ampliación y reformas en las redes de distribución de la cooperativa; energía eléctrica facturada y pérdidas por transporte, transformación y distribución e importes percibidos por alumbrado público y particular; licitación, dirección técnica y ejecución de obras y adquisición de equipamiento; número de conexiones; suministros gratuitos a entidades oficiales e instituciones de bien público; modificaciones de las tarifas), cuestiones referidas al personal administrativo y técnico (ocupación de mano de obra local y retribuciones), además de informaciones sobre actos cooperativos y contactos con entidades cooperativas de primero y segundo grado. En tanto que en los balances se registran diversas informaciones contables: ingresos y egresos generales durante el período, demostración de la incidencia de los gastos sobre el costo del $\mathrm{kWh}$ facturado, desglose de la cuenta gastos generales, balance general del ejercicio, demostración de la cuenta ganancias y pérdidas, proyectos de distribución de las utilidades líquidas e informes del síndico.

Dentro de la documentación generada por la cooperativa en el ejercicio de 
su actividad ocupan un lugar muy importante los registros contables, los que según Jordi Nadal "encierran el auténtico latir del negocio", porque sin duda son la base para la dirección de su (negocio) actividad. (NADAL, 1983:100) En las empresas la contabilidad es el método más usado para llevar convenientemente las cuentas pues permite recoger todas las operaciones de relevancia económica y justificar documentalmente las acciones contables y por eso, dentro de esos registros, además de los libros contables, es dable encontrarse con otro tipo de documentación como facturas, órdenes de compra, inventarios y documentos bancarios. ${ }^{8}$ Ciertamente, no todas las cooperativas son iguales, pues cada ramo tiene su documentación específica y también su tamaño puede llegar a determinar la calidad de sus archivos, pero en lo que se refiere a las eléctricas los documentos básicos que conviene ubicar y consultar son: los libros de contabilidad, la facturación, los reportes de producción, los instrumentos de deuda, los registros de socios, los movimientos de acciones, los contratos de trabajo y las cuentas de sueldos.

Igualmente importante es el libro de registro de asociados, que en muchos estatutos se denomina padrón de asociados. Ahora bien, pese a la utilidad práctica de ese registro para la organización interna de la cooperativa, pues le permite conocer quienes son sus asociados en el momento en que la constatación de tal circunstancia pudiese tener alguna relevancia, lamentablemente en la ley $\mathrm{N}^{0} 11.388$ no fue contemplado por ninguna disposición de manera que durante su vigencia la confección de tal registro quedó al arbitrio de cada cooperativa, si bien se ha podido comprobar que por lo general en los estatutos de las cooperativas surgidas con anterioridad a la ley $\mathrm{N}^{\mathrm{o}}$ 20.337, que finalmente cubrió ese vacío legal, se disponía la confección de tal padrón aunque también que fueron muy pocos los que llegaron a determinar, con adecuada precisión, "las distintas circunstancias fáctico-jurídicas que influyen, para alcanzar la depuración adecuada del mismo y su saludable actualización" y la forma del ingreso a los padrones, pero no cabe duda que en ellos deberían figurar inicialmente la totalidad de las personas que integraron la

$8 \mathrm{Al}$ respecto se debe recordar que la función de la contabilidad cooperativa es la de "controlar, registrar y demostrar instruida y documentalmente no sólo el proceso y magnitud, cifras y conceptos de la operación reflejada, situación patrimonial y financiera y resultados económicos de cualquier entidad sino también el comportamiento de todos y cada uno de los factores intervinientes [...]" (JUNYENT VÉLEZ Y BERTOSSI, 1987: 99). 
asamblea constitutiva, firmaron las tres copias del acta fundamental y que dieron nacimiento a la cooperativa. (JUNYENT VÉLEZ Y BERTOSSI, 1987: 144) De todos modos y aunque su confección no siempre fue obligatoria es conveniente señalar que en ese padrón se tendría que llevar un registro, debidamente ordenado y organizado, en el que se inscriban los nombres y condiciones de las personas físicas o jurídicas que han sido admitidas en carácter de asociados, por decisión de los órganos competentes, y en el que también se tendría que hacer constar las depuraciones, es decir, cuáles son los asociados que han hecho uso del derecho de retiro, aquellos otros que fueron por alguna razón jurídica -como cesión, fallecimiento y otra causa similareliminados o sustituidos y, finalmente, aquellos que hubiesen sido excluidos o expulsados por resolución válida de órgano competente.

Pero no se agota allí el contenido del acervo documental de una cooperativa. También hay otras documentaciones importantes y muy variadas que dan cuenta de su accionar diario y que pueden ser útiles al investigador. Entre ellas, y en un listado no exhaustivo, podemos mencionar las minutas de reuniones, la correspondencia, los folletos de propaganda, las órdenes internas, los comunicados a los socios, y en el caso de las cooperativas eléctricas, especialmente, los informes y planos técnicos.

A simple vista queda claro que la documentación que es esperable encontrar en los archivos de las cooperativas eléctricas es muy variada y decimos que "es esperable encontrar" porque en realidad de toda ella las únicas que, con más o con menos reticencia, los consejos de administración ponen a disposición de los investigadores son las tres primeras; es decir, las actas de asambleas, las actas de las reuniones de los consejos de administración y los informes o memorias anuales. El resto permanece inalcanzable para el investigador y por lo tanto éste debe recurrir a fuentes indirectas, ${ }^{9}$ las que en realidad de cualquier modo debiera consultar para poder completar, profundizar y enriquecer su análisis cruzándolas con las generadas por la propia cooperativa.

Por último, dentro de la documentación propia de las cooperativas, otra fuente de información ineludible son sus boletines informativos, generalmente

9 En otro trabajo (SOLVEIRA, 2007) se ha hecho referencia a esas fuentes indirectas, indicando la información complementaria que sobre la vida de las cooperativas eléctricas podemos encontrar en los archivos de las administraciones públicas y en los archivos privados. 
de distribución gratuita y que constituyen el medio a través del cual los consejos de administración mantienen informados a los asociados y promueven en ellos el espíritu cooperativo, y en los que si bien encontramos datos ya conocidos a través de aquellos otros documentos, también incluyen otro tipo de noticias igualmente útiles: notas y artículos que nos permiten ampliar el conocimiento acerca de la visión que se tenía de la importancia económica y social de las cooperativas -vertidas ellas por los propios consejeros, por cooperativistas destacados o por representantes de los poderes públicos-, de las relaciones de la cooperativas con otras entidades similares -eléctricas, agrarias, tamberas, etc.existentes en el país y con las organizaciones que las fueron agrupando a través del tiempo, datos sobre incorporación de nuevos asociados o sobre el retiro de otros, sobre transferencias de acciones, sobre el avance de las redes de distribución de la cooperativa. $\mathrm{Al}$ respeto, lo importante es que en el caso de las cooperativas cordobesas y de las bonaerenses que han sido estudiadas hasta ahora, todos estos materiales están al alcance de los investigadores.

Los boletines informativos de las cooperativas que hemos tenido oportunidad de consultar son Nuestra Luz - de la Cooperativa de Luz y Fuerza Motriz de Río Tercero- y Luz -de la Sociedad Cooperativa de Electricidad de Córdoba- y creo que una aunque somera descripción de la información que los mismos brindan puede ser muy ilustrativa.

Del primero de ellos hemos consultado los tres números aparecidos en el año 1934 -cuyo tiraje era de mil ejemplares-, y 43 números -uno de ellos extraordinario- aparecidos entre febrero de 1937 y diciembre de 1940, bajo la dirección del señor Carlos A. Angeloz. El objetivo fundamental perseguido con esta publicación, claramente explicitado en el primer número de 1937, fue la de informar a los asociados acerca de l(a obra)o realizad(a)o por el consejo de administración. Por ello, al dar cuenta de esa obra, con frecuencia el boletín incluye en sus páginas copia de documentos oficiales o de iniciativas relacionadas con la cooperativa y producidos por las autoridades municipales, provinciales y nacionales; información relacionada con la integración de los consejos de administración y sus reuniones, con la cantidad accionistas y de 
usuarios y el nombre de los nuevos accionistas, ${ }^{10}$ con los intereses accionarios y retornos, con operaciones bancarias y con las gestiones destinadas a obtener créditos que permitieran financiar las obras de infraestructura eléctrica y edilicias así como de las licitaciones públicas de tales obras, con la transferencia de acciones, con estudios acerca del consumo y del robo de energía, y con conferencias sobre cooperativismo dadas en distintos puntos de la provincia y a las que habían asistido o habían sido oradores los representantes de la cooperativa, en este último caso se agregaba una copia textual de la disertación. A través de este medio se efectuó también la convocatoria a las asambleas ordinarias y se informó acerca de las reformas de los estatutos de la sociedad; se dieron a conocer reglamentaciones técnicas respecto de las bajadas y ubicación de los medidores de energía, protección de las instalaciones y artefactos eléctricos y, partir de 1937, en todos sus números se incluyó asimismo una copia del balance de comprobación y saldos correspondientes al mes anterior. Otras informaciones que se pueden encontrar están referidas a la puntualidad en el pago de las cuotas de acciones y a la eliminación de los socios morosos -con inclusión en cada caso del nombre del accionista-, a las tarifas eléctricas, a la creación de nuevas cooperativas en distintos lugares del país, a asambleas que convocaban a delegaciones de poblaciones del interior provincial y que se proponían estudiar -desde la faz técnica- la formación de nuevas cooperativas, a la "guerra a la cooperación eléctrica" -en alusión al avance del monopolio eléctrico en el país y a la persecución de que eran objeto las sociedades cooperativas-, al progreso del movimiento cooperativo en el país y en el mundo, a las gestiones para lograr la importación de equipamiento eléctrico libre de derechos aduaneros.

De los boletines informativos de la Sociedad Cooperativa de Electricidad de Córdoba, en el Archivo Histórico Municipal de Córdoba hemos podido consultar tres números, ${ }^{11}$ cuyo contenido es diverso e incluye notas editoriales

\footnotetext{
10 Así por ejemplo, en el $\mathrm{N}^{\circ}$ 2, de agosto de 1934, se informaba con orgullo que el diputado provincial Dr. Tomás Ojea se había inscripto con varias acciones y que había sido nombrado presidente honorario de la comisión asesora del directorio.

11 Dos de ellos corresponden a un primer boletín, del cual en ese archivo se conservan los dos primeros números -marzo y diciembre de 1936- y el tercero es una revista denominada $L u z$, de la cual sólo se conserva el $\mathrm{N}^{0} 130$ de setiembre de 1940. Como ese número corresponde al Año III, podemos suponer que esta revista de distribución gratuita debe haberse comenzado a editar a comienzos de 1938 y que su frecuencia debe haber sido semanal; además, como sus contenidos
} 
acerca del problema eléctrico, del cooperativismo y de las obras a construir por la cooperativa; copias de documentos oficiales y de la correspondencia intercambiada entre el presidente de la cooperativa y autoridades municipales, provinciales y nacionales; informaciones contables (demostración de entradas y salidas de caja, de la cuenta de gastos de organización y de pérdidas y ganancias; informe y balance general y de cuentas corrientes e informes del síndico); ejemplares de las boletas de adhesión de nuevos socios, actas de asambleas y de sesiones del consejo de administración, convocatorias a asambleas y copia de los estatutos de la cooperativa. Por cierto que en este caso también, se aclaró en forma explícita que el boletín era el órgano oficial de la cooperativa, el portavoz de sus actividades.

En las últimas dos décadas se ha advertido que una historia de la empresa centrada exclusivamente en los componentes económicos no es ya satisfactoria ni suficiente porque no permite explicar el verdadero alcance histórico de las transformaciones generadas por las empresas; es decir, sólo reemplazando ese reduccionismo económico y fijando la atención en el componente social de tales entidades, es posible llegar a comprender el comportamiento humano. En este mismo sentido, hace ya más de una década Giulio Sappelli señaló muy acertadamente, a nuestro juicio, que la empresa es una asociación de personas y una construcción social, porque:

\begin{abstract}
las empresas incorporan siempre muchas más facetas que sus importantísimos resultados económicos y que sus, a menudo, radicales cambios organizativos. Las empresas son la acumulación de un patrimonio de conocimientos, de culturas, de valores profesionales y de valores morales (SAPPELLI, 1996: 475).
\end{abstract}

Ahora bien, aunque es obligado reconocer que la historiografía argentina no cuenta con demasiados estudios de empresa y en consecuencia no le es aplicable esa crítica de Sappelli al enfoque reduccionista de una historia de (empresas) las mismas centrada exclusivamente en el desempeño económico y productivo, no por ello debemos desechar su propuesta de no quedarnos sólo en el análisis de los intercambios y prácticas económicas de las empresas y, en el caso específico de las cooperativas eléctricas, creemos que sería válido intentar en lo posible y a medida que se vaya avanzado en los estudios de caso, una

son similares, también es posible suponer que la revista reemplazó al primer boletín y que lo único que cambió fue el formato y el nombre. 
historia encarada por la vía de una perspectiva interdisciplinar porque las cooperativas, tal vez más que cualquier otro tipo de empresa, exigen ese (tipo) modo de aproximación que permite resaltar su carácter de agente modificador del entorno en todos sus aspectos -económico, tecnológico, geográfico, social, cultural-, convirtiendo a su archivo en la memoria privilegiada de la comunidad a la que pertenece. Es decir, sin descuidar el estudio de su evolución económica, creemos que sería saludable incorporar también el de otras dimensiones de la experiencia cooperativa.

$\mathrm{Al}$ respecto y si bien en referencia a las empresas en general, pero aplicable al estudio del fenómeno cooperativista en tanto "factor de poder en el ámbito local que modela las actitudes humanas" y se manifiesta en una "compleja red de interacciones”, José Andrés González Pedraza nos sugiere, por ejemplo, abrir un diálogo entre la historia y la antropología "para convertir en objeto de estudio cuál es el origen y cómo se articulan las actitudes humanas" en el contexto, en nuestro caso, de las cooperativas (GONZÁLEZ PEDRAZA, 2006). No obstante, como el archivo de las cooperativas es tanto un conjunto de series documentales inexistentes en otro tipo de archivos, como un conjunto de fuentes complementarias que ofrecen un enorme interés para emprender una investigación de carácter interdisciplinar, junto a ese ya ineludible enfoque multidisciplinario que hará posible una visión más amplia de un fenómeno tan complejo como lo es el cooperativismo, en relación a las fuentes y al trabajo con ellas es también necesario aceptar las limitaciones de nuestra disciplina y la conveniencia de servirnos de los conceptos y técnicas que ponen a nuestro alcance otras ciencias sociales y acentuar aquel diálogo puesto en práctica ya por los primeros analistas. Ciertamente, cuando se comienza a trabajar sobre la historia de una cooperativa rápidamente se advierte que, para comprender el mensaje de los documentos, nos es necesario incorporar a nuestra formación disciplinar saberes específicos propios de otras ramas de las ciencias sociales o bien recurrir a la ayuda de otros profesionales.

$\mathrm{Si}$ se trata de los registros contables -balances, presupuestos-, el investigador necesitará conocer de contabilidad porque, como muy bien afirma María José García Gómez, "la contabilidad es esencialmente un problema de sumas y restas con significado"; si en cambio analiza documentos que dan cuenta de las decisiones empresariales, necesitará de nociones, aunque sean 
rudimentarias, de administración de empresas. (GARCÍA GÓMEZ, 2001: 87) En el caso de las cooperativas eléctricas una necesidad similar se plantea respecto de la actividad específica de producción y distribución de electricidad, cuyo estudio le requerirá recurrir a profesionales de la ingeniería. Es decir, aquí aparece otra cuestión no menos importante y es que una comprensión adecuada de la historia de una cooperativa eléctrica a través de sus fondos documentales supone, inevitablemente, un enfoque interdisciplinario que permita al historiador situarse -parafraseando a aquella colega española- en una mejor capacidad de descubrir la toma de decisiones y el desarrollo de la cooperativa, así como plantear hipótesis para su comprobación (GARCÍA GÓMEZ, 2001: $89)$.

En síntesis y como cierre de estas breves reflexiones, debo insistir en señalar que el reciente descubrimiento del cooperativismo eléctrico como objeto de estudio por la historiografía argentina, no ha dado como resultado demasiadas investigaciones que arrojen luz acerca de un fenómeno que comienza a producirse en nuestro país a partir de la segunda mitad de la década de 1920, y que probablemente ello se deba a que la cuestión no ha interesado aún a muchos colegas, o bien, a que tal interés exista pero se vea limitado por las dificultades para acceder a las fuentes propias de las cooperativas. En esta artículo se ha prestado especial atención a este último problema y se ha argumentado a favor de la pronta apertura de los fondos documentales de las cooperativas eléctricas a la investigación histórica, destacando que con esa decisión las mismas habrán de contribuir a una forma de conciencia histórica que valorice el esfuerzo material y humano que sin dudas demandará la organización de sus archivos. Con esto espero dejar abierto un debate hoy por hoy ineludible.

\section{Bibliografía}

ÁLVAREZ, Luis Alonso. Fuentes para la investigación de la historia empresarial en la España de los siglos XIX y XX. IN: América Latina en la Historia Económica. Boletín de Fuentes, $\mathrm{N}^{0}$ 15, enero-junio 2001, pp. 13-36.

Asociación de Productores y Distribuidores de Electricidad. Las cooperativas y los servicios eléctricos. Buenos Aires: 1942.

BELTRAMO, Constancio Francisco. El cooperativismo en Córdoba. IN: Revista 
de Economía, Banco de la Provincia de Córdoba, Nº 19, Tomo XIII, 1963, pp. $39-62$.

Cooperativas: comentario de la ley 20.337. Córdoba: UNC, Facultad de Ciencias Económicas, 1975.

BLOCH, Marc. Introducción a la historia. Buenos Aires: FCE, 1982.

CALLEJO, Alfredo Victorino. Las cooperativas eléctricas, la integración y su entorno", en: Cuadernos de Economía Social, No 8, sepiembre de 1999, pp. 2934 .

COLACIOPPO, Vicente. Sociedades cooperativas. Buenos Aires: Contabilidad Moderna, 1967.

COMÍN, Francisco. La empresa pública en la España contemporánea: Formas históricas de organización y gestión. Madrid: Documento de Trabajo de la Fundación Empresa Pública, 1995.

y ACEÑA, Pablo Martín Los rasgos históricos de las empresas en España: un panorama. Madrid, Documento de Trabajo 9605 de la Fundación Empresa Pública, Programa de Historia Económica, 1996.

CORONA MARTÍNEZ, Enrique U. Treinta y cinco años de cooperación eléctrica argentina. IN: La solución cooperativa, Ciclo de Conferencias 1947-1964, Buenos Aires: Círculo de Estudios Cooperativos, 1965.

CREMASCHI, José Mario. Cooperativas eléctricas en la provincia de Mendoza. Mendoza: Dirección de Estadísticas e Investigaciones Económicas, 1971.

CRUZ MUNDET, José Ramón. Archivo y empresa: más allá de la historia, Universidad Carlos III, 2005, Sitio de Internet: http://www.tstrevista.com/descargas/dossier8.pdf.

D’ATRI, Raúl Isidoro. El proceso de gestación de la cooperativa popular de electricidad de Santa Rosa Ltda. (La Pampa), Revista de Idelcoop, Año 1984, Volumen 11, $\mathrm{N}^{\circ} 40$.

GARCÍA GÓMEZ, María José. Reflexiones para hacer la historia de la empresa en el México de los siglos XIX y XX, América Latina en la Historia Económica. Boletín de Fuentes, $\mathrm{N}^{\mathrm{O}}$ 15, enero-junio de 2001, pp. 73-93.

GONZÁLEZ PEDRAZA, José Andrés. Los archivos de empresa: una aproximación, Archivamos (Revista de la Asociación de Archiveros de Castilla y León), ${ }^{0}$ 36-37, 2000, pp. 40-43.

. Instrumentos de información en Archivos de empresa: la Guía del Archivo de Sociedad Anónima Hullera Vasco-Leonesa", Actas de las III Jornadas Internacionales sobre Patrimonio Industrial (INCUNA- Asociación de Arqueología Industria, Gijón, 27-29 de junio de 2001). Gijón: INCUNA, 2002, pp. 77-87.

. Investigar en Archivos de empresa: el Archivo de Sociedad Anónima Hullera Vasco-Leonesa, Fundación Hullera Vasco-Leonesa, 2006, Sitio de Internet:

http://www.usc.es/estaticos/congresos/histeco5/b21_gonzalez_pedraza.pdf.

Intercoop. El movimiento cooperativo eléctrico argentino. Una puesta al día, Cuadernos de Cultura Cooperativa, $\mathrm{N}^{\circ}$ 43, Buenos Aires, 1972. 
JUNYENT VÉLEZ, Francisco y BERTOSSI, Roberto Fermín. La Cooperativa. Córdoba: EDIAR, 1987.

LÓPEZ, Diego Andrés. La gestión de las cooperativas de servicios públicos. El caso de las Cooperativas Eléctricas de la Provincia de Buenos Aires, Revista del Instituto de la Cooperación, $\mathrm{N}^{\circ}$ 134, 2001, pp. 334-360.

LLUCH, Andrea y SÁNCHEZ, Laura. De movimiento popular a empresa. El cooperativismo eléctrico en la Pampa (1925-1950). Santa Rosa (La Pampa/Argentina): FEP, 2002.

MARQUIEGUI, Dedier Norberto y TARTAGLIA, María Teresa. De la sociedad anónima por acciones al cooperativismo: el caso de la Cooperativa Eléctrica y de Servicios Públicos Lujanense Ltda., 1911-2000, CAYAPA Revista Venezolana de Economía Social, año 3, $\mathrm{N}^{\circ}$ 5, 2003, pp. 84-104.

The visible hand: el cooperativismo ante los desafíos del mercado. La Cooperativa Eléctrica de Servicios Públicos Lujanense Limitada, Revista de la Cooperación Internacional, vol. 37, $\mathrm{N}^{\mathrm{o}}$ 1, 2004, pp. 113-138.

NADAL, Jordi. Archivos industriales en Cataluña, Banco de España, Actas del primer Congreso sobre Archivos Económicos de Entidades Privadas, Archivo Histórico del Banco de España, Madrid, 1983.

RÍO, Jorge del. Cooperativas de electricidad y usinas populares. Buenos Aires: s/e, 1940.

RODRÍGUEZ, María Elena. La Cooperativa de Luz y Fuerza de Río Tercero: su origen y desarrollo entre 1933 y 1945, XIX Jornadas de Historia Económica, San Martín de los Andes, soporte digital, 2004.

. La Cooperativa de Río Tercero: su gestión en torno al suministro de agua potable, 1943-1953, X Jornadas Interescuelas/Departamentos de Historia, Rosario, soporte digital, 2005.

. La Cooperativa de Río Tercero: una institución que creció de acuerdo a las necesidades de su comunidad, 1960-1980, XX Jornadas de Historia Económica, Mar del Plata, soporte digital, 2006.

. La Cooperativa de Río Tercero: una institución al servicio de la comunidad, 1933-1953, Mundo Agrario. Revista electrónica de estudios rurales, $\mathrm{N}^{\mathrm{O}}$ 12, La Plata, 2006.

SAPELLI, Giulio. La construcción social e histórica de la empresa: para un nuevo modelo teórico. IN: COMÍN, Francisco y ACEÑA, Pablo Martín (eds.). $L a$ Empresa en la Historia de España. Madrid: Civitas, 1996, pp. 473-487.

SCORTEGAGNA, Renzo. La ricerca della qualità attraverso l'organizzazione dell'archivio, L'archivio nell'organizzazione d'impresa. Venezia, 1993, pp. 2940.

SEGURA, Pedro. Los archivos de empresa: objeto de investigación, Actas de las Jornadas Archivos e Investigación (Murcia, 13-15 noviembre 1991), Murcia, 1996, pp.151-162.

SMITH, George David y STEADMAN, Laurence E. Present Value of Corporate History, Harvard Business Review, 1981, pp. 164-173.

SOLVEIRA, Beatriz R. De cooperativas eléctricas a cooperativas de servicios 
públicos. El cooperativismo eléctrico en la provincia de Córdoba, XIX Jornadas de Historia Económica, San Martín de los Andes, soporte digital, 2004.

Estado, cooperativismo eléctrico y electrificación rural en Córdoba (1930-1980, X Jornadas Interescuelas/Departamentos de Historia, Rosario, soporte digital, 2005.

. Estado, cooperativismo eléctrico y electrificación rural. La experiencia cordobesa entre 1930 y 1980, Mundo Agrario, Revista electrónica de estudios rurales, vol. 6, $\mathrm{n}^{\mathrm{0}}$ 12, La Plata, 2006.

VEYNE, Paul. Cómo se escribe la historia. Foucault revoluciona la historia. Madrid, Alianza, 1984.

VILORIA DE LA HOZ, Joaquín. El uso de las fuentes notariales con fines de investigación: el caso de la historia empresarial en el Caribe colombiano. América Latina en la Historia Económica. Boletín de Fuentes, $\mathrm{N}^{0}{ }_{15}$, enerojunio 2001, pp. 59-71.

ZUBIAUR, Guillermo Benjamín. Aspectos del movimiento cooperativo eléctrico, Universidad Nacional de La Plata, Facultad de Ciencias económicas, Instituto de la Producción, Serie Contribuciones, $\mathrm{N}^{\circ}$ 154, 1964.

Colaboração recebida em 20/02/2009 e aprovada em 17/04/2009. 